Article

\title{
Social Exclusion and Effectiveness of Self-Benefit versus Other-Benefit Marketing Appeals for Eco-Friendly Products
}

\author{
Ahyoung Yu and Seunghee Han *D \\ School of Business Administration, College of Business \& Economics, Chung-Ang University, Seoul 06974, Korea; \\ 3ayoung@naver.com \\ * Correspondence: shan@cau.ac.kr
}

check for updates

Citation: Yu, A.; Han, S. Social Exclusion and Effectiveness of Self-Benefit versus Other-Benefit Marketing Appeals for Eco-Friendly Products. Sustainability 2021, 13, 5034 https://doi.org/10.3390/su13095034

Academic Editor: Mario D’Amico

Received: 30 March 2021

Accepted: 28 April 2021

Published: 30 April 2021

Publisher's Note: MDPI stays neutral with regard to jurisdictional claims in published maps and institutional affiliations.

Copyright: (c) 2021 by the authors. Licensee MDPI, Basel, Switzerland. This article is an open access article distributed under the terms and conditions of the Creative Commons Attribution (CC BY) license (https:// creativecommons.org/licenses/by/ $4.0 /)$.

\begin{abstract}
Despite the growing need, marketers of eco-friendly products have not yet identified the most effective ways to attract consumers to their products. The current research explores the effectiveness of two distinct marketing appeals for eco-friendly upcycling products. In particular, an experiment is conducted to examine the hypothesis that the psychological state, especially feeling socially excluded, and marketing appeal type (self-benefit vs. other-benefit) will interact to affect the effectiveness of the promotion. The results suggest that self-benefit appeals are more effective than other-benefit appeals for encouraging positive purchase intentions when consumers feel socially excluded. Importantly, the effect of social exclusion is moderated by how lasting consumers think their social exclusion experience will be. The more stable consumers think their social exclusion experience will be, the more positively they respond to self-benefit appeals as compared to otherbenefit appeals. The results suggest a way that marketers could tailor their marketing message to consumers' psychological state.
\end{abstract}

Keywords: social exclusion; eco-friendly products; marketing appeal

\section{Introduction}

Rapid economic growth has increased the economic well-being of mankind. According to the report from the Worldwatch Institute [1], rising consumption has helped meet basic needs and create jobs. However, this also has taken a toll on the natural systems we all depend on, aggravating environmental problems such as resource depletion, global warming, and climate change. Consumers in the developed and developing world have especially contributed to the problem by having a lock on unsustainable over-consumption for decades to the detriment of the environment. As the world struggles with an unsustainable rate of consumption, companies and consumers alike are recognizing the need to adopt an environmentally conscious way of consumption. Various industries are embracing this movement and innovating ways to reduce, reuse, or recycle products and materials in their production. For example, Patagonia produces fleece jackets made from recycled plastic bottles and Nike now recycles manufacturing scraps into new footwear products.

Recently, upcycling - the creation or modification of a higher value product from used or waste materials and products-is gaining attention as a form of sustainable ecofriendly practice (Singh, Sung, Cooper, West, \& Mont, 2019) [2]. For example, in the fashion industry, there are innovative brands that use fabric offcuts from luxury designers to create imaginative new outfits or brands that reuse fabrics from army parachutes or truck tarpaulins to create outerwear or functional daily bags. One report from BBC revealed that around $85 \%$ of textiles thrown away are either dumped into landfill or burned. It has been estimated that the average American throws away approximately $37 \mathrm{~kg}$ of clothes every year [3]. Given this, upcycling in fashion is certainly good news for the environment. Upcycling reduces waste, increases material efficiency, and reduces energy consumption. Moreover, it has the potential to create new employment opportunities and encourage the culture of sustainable consumer behavior. 
Despite its numerous potential benefits however, upcycling has fallen short of gaining popular attention even in fashion industry. It is unfortunate that upcycling remains a niche practice despite the fact that the consumer sentiments seem to be ripe for sustainable fashion. Consumers, especially Millennials, say they want brands that embrace meaning and practice sustainability. However, even consumers who report interest toward upcycling products are yet to follow through with actual purchase. Both marketing practice and academic research for promoting upcycling products are still at their very infancy. In order to develop upcycling from niche to mainstream, much research is needed (Singh et al., 2019) [2]. Especially with regard to consumer behavior, research examining the effects of consumer traits-e.g., individual characteristics like need for uniqueness, moral identity, and so forth-in response to promotion of upcycling products, or research exploring effects of various marketing appeals-e.g., assertive vs. suggestive language, long-term vs. short-term time frame-is required.

The current research explores how marketing appeals for upcycling products could be made better by focusing on two factors, a person factor and a marketing stimulus factor, and interaction between the two. For the person factor, we look at a prominent consumer characteristic of modern days, i.e., feelings of social exclusion. For the marketing stimulus factor, we look at message appeal type, i.e., appealing with self-benefit versus appealing with other-benefit. That is, the present study seeks to test the effectiveness of two distinct marketing appeals for eco-friendly upcycling products. In particular, we examine whether the psychological state, especially feeling socially excluded, and marketing appeal type (self-benefit vs. other-benefit) will interact to affect the purchase intention of upcycling products. We hope to shed light on how best to craft advertising message for upcycling products to those consumers who often feel socially excluded in their daily lives.

\section{Theoretical Background}

\subsection{Social Exclusion}

In modern society, feelings of social exclusion are not limited to those who are socially or economically vulnerable. Social exclusion is a rather common experience in the lives of modern consumers. People often experience incidents of feeling excluded or being rejected from acquaintances, colleagues, and friends (Baumeister, DeWall, Ciarocco, \& Twenge, 2005; Kwilinski, Vyshnevskyi and Dzwigol, 2020; Sjåstad, Zhang, Masvie, and Baumeister, 2021; Williams, 2007) [4-7]. The personalization of modern society, increase in single-person households, and social-distancing during the COVID-19 era have made such experiences even more prevalent. Research suggests that the heavy use of social media paradoxically tends to exacerbate feelings of social isolation, instead of making people feel socially connected (Primack et al., 2017) [8].

Since social exclusion frustrates the fundamental human need to belong (Baumeister \& Leary, 1995) [9], the anticipation and experience of social exclusion evoke a variety of emotions and lead people to resort to coping strategies ranging from increased hostility toward general others (DeWall, Twenge, Gitter, \& Baumeister, 2009) [10], withdrawal from social contexts (Twenge, Baumeister, DeWall, Ciarocco, \& Bartels, 2007) [11] and sometimes renewed efforts toward social re-connection (Gardner, Pickett, Jeffries, \& Knowles, 2005; Maner, DeWall, Baumeister, \& Schaller, 2007) [12,13]. More centrally to the current research, studies on consumer judgments and choice revealed that individuals who experience social exclusion tend to conform to others in their product choice in an effort to regain social acceptance (Kim and Han, 2014; Mead et al., 2011; Williams, Cheung and Choi, 2000) [14-16]. This is in line with research arguing that social exclusion generally increases focus on other people and, relatedly, prosocial behaviors (Williams, 2007) [7]. Other studies of consumer choice, however, documented that individuals who experience social exclusion tend to seek individual uniqueness and exhibit decreased interest in helping (Twenge et al., 2001; Twenge et al., 2007; Wan et al., 2014) [11,17,18], a pattern inconsistent with conformity or prosociality. 
Considering these mixed findings in the literature, the primary purpose of the present research is to explore how social exclusion might lead consumers to respond to marketing appeals of eco-friendly upcycling products.

\subsection{Message Appeal Type}

Suppose that you come across an advertisement for a messenger bag from an upcycling brand. The advertisement copy emphasizes the bag's eco-friendliness and says, "Choose it for YOU." Conversely, the advertisement copy says, "Choose it for the ENVIRONMENT." How would you react to these promotions? What factors affect your reaction toward them? Would the psychological state you currently experience (e.g., social exclusion) influence your response? That is, would your reaction be different if you feel excluded or accepted at the time when you saw these advertisements? Answering these questions would help upcycling brands create an effective promotional campaign and target it with greater efficacy.

Self-benefit appeals and other-benefit appeals have frequently been used to encourage prosocial behavior and have caught attention from many marketing researchers (e.g., Brunel and Nelson 2000; Fisher, Vandenbosch and Antia 2008; Kim and Kim, 2020; White and Peloza, 2009) [19-22]. Self-benefit appeals highlight consumer as main beneficiary whereas other-benefit appeals highlight some other individual or society at large as main beneficiary of their behavior. The results found in the existing literature are generally mixed as to whether self-benefit or other-benefit appeals are more effective in encouraging prosocial behavior.

Some suggest that self-benefit appeals are more successful in encouraging prosocial behavior because self-benefit appeals provide permission to engage in behaviors that are difficult to justify with conventional cost-benefit analysis (e.g., De Groot \& Steg, 2008; Stern, 2000) $[23,24]$. To the contrary, some suggest that other-benefit appeals are more successful in encouraging prosocial behavior. Especially with eco-friendly products, it was found that consumers responded more positively to the message appealing to others' interests than to message appealing to self-interest. For example, Peattie and Crane (2005) found that eco-friendly products that provide future benefits to the entire consumer can increase purchase intentions more effectively than eco-friendly products that only provide consumers' individual benefits [25].

Some argue that consumers' psychological traits and states need to be taken into consideration. Taylor and Todd (1995) found that consumers with low involvement in environmental issues responded favorably to their own self-benefit appeals, while consumers with high involvement in environmental issues responded equally to both self-benefit and other-benefit appeals [26]. White and Peloza (2009) reported that other-benefit appeals generate more charitable support than self-benefit appeals for consumers with high public self-awareness [22]. Baek, Yoon, Kim and Kim (2019) demonstrated that consumers who feel socially excluded reacted more positively to other-benefit appeals than to egoistic, self-benefit appeals in charitable advertising [27].

\subsection{The Present Research}

The current research seeks to examine the interaction between feelings of social exclusion and self- vs. other-benefit appeals in the context of promoting for eco-friendly upcycling products.

This is meaningful because social exclusion has become common experience for modern consumers and has been shown to influence consumers' choice and decision making in meaningful ways (e.g., Su, Jiang, Chen, \& DeWall, 2017; Wan, Xu, \& Ding, $2014)[18,28]$. In addition, due to advances in digital technology and analytic techniques, marketers now have tools to reasonably infer consumers' psychological states by tracking a broad variety of digital footprints collected in real time (Matz and Netzer, 2017) [29]. This implies that understanding the intricate interaction between consumers' psychological states, like social exclusion, and promotional message is a worthwhile endeavor that will 
provide opportunities to personalize marketing contents to the immediate psychological needs of target consumers.

In addition, we believe that marketing appeals for eco-friendly upcycling products should be different from marketing appeals for charitable donation which has been the focus of much of the previous literature. After all, the core product consumers purchase in each case is different. Unlike charitable donations, eco-friendly upcycling products serve other core objectives than 'helping others'. Thus, purchasing eco-friendly upcycling products is not something that will immediately be recognized as laudable prosocial behavior that enhances consumers' social standing or chance of social re-connection. That is, purchasing upcycling products is unlikely to be a way to restore social bonds and remedy social exclusion. This will lead socially excluded consumers to remain rather selffocused and respond more positively to self-benefit appeals than to other-benefit appeals for upcycling products. Thus, we hypothesize as follows:

Hypothesis 1. The psychological state (i.e., social exclusion) and marketing appeal type (self-benefit vs. other-benefit) will interact to influence purchase intention of upcycling products.

Hypothesis 1a. Participants who feel socially excluded will be more likely to respond positively to upcycling products promoted with self-benefit appeals than with others-benefit appeals.

According to the attribution theory (Weiner 1986), the perceived stability of a negative event guides subsequent behavior such that people are more likely to move away from prior pursuits to protect themselves from further psychological pain when they assess the negative event to be stable [30]. In the case of excluded individuals, focusing on self instead of focusing on others can be viewed as such manifestation. Indeed, Wan, $\mathrm{Xu}$, and Ding (2014) found that the effects of social exclusion on consumer behaviors depend on their appraisal of the exclusion situation [18]. When excluded individuals perceive that their experience of social exclusion is stable (vs. unstable), they tend to perceive themselves to be unique and exhibit greater preference for distinctive products. This pattern of behavior is consistent with independent and individualistic tendency to focus on the ' $\mathrm{I}$ ' (vs. interdependent and prosocial tendency to focus on the ' $\mathrm{We}$ ').

Based on this line of research, we further hypothesize that the way consumers assess their situation of social exclusion matters. That is, if excluded individuals perceive the situation to be rather stable, their focus on self will be heightened and thus the message focusing on benefit for the society at large will fall on deaf ears. That is, they will respond better to self-benefit appeals than to other-benefit appeals. On the other hand, if excluded individuals perceive the situation to be unstable or temporary, they will be less likely to focus solely on themselves and be more open to messages focusing on benefit for the society at large. That is, they will not necessarily respond better to self-benefit appeals than to otherbenefit appeals. We thus expect that social exclusion will interact with perceived stability of social exclusion to affect consumers' reaction. We formally hypothesize the following:

Hypothesis 2. For socially excluded participants, the interaction effect of their psychological state and marketing appeal type on purchase intention of upcycling products will be moderated by their assessment of how stable their situation will remain.

Hypothesis 2a. Among socially excluded participants, the more stable one perceives one's social situation to be, the more positively one will respond to self-benefit appeals as compared to otherbenefit appeals of upcycling products.

\section{Experiment}

In order to test the causal hypotheses between the variables, we choose to design an experimental study. Specifically, we experimentally test the role of social exclusion and the appraisal of it in determining the effectiveness of marketing appeal type (other-benefit vs. self-benefit) in the context of promoting eco-friendly upcycling products. 


\subsection{Methods}

One hundred and eighty people from Seoul and the surrounding metropolitan area successfully completed the online experiment. Most participants were in their 20s or 30 s and $42.2 \%$ were males and $57.8 \%$ were females. Fifty five percent of participants reported an income between KRW 1.5 million (approximately USD 1500) and KRW 3 million (approximately USD 3000) and 32.2\% reported income less than KRW 1.5 million.

The experiment was a 2 (social state: exclusion vs. inclusion) $\times 2$ (appeal type: selfbenefit vs. other-benefit) between-subjects design and participants were randomly assigned to one of the four types of questionnaires each matching one of the four conditions.

To manipulate the state of social exclusion, we used a recall and writing task adapted from previous research (Wan et al., 2014) [18]. The participants were asked to read the provided scenario describing exclusion vs. inclusion experience in the context of making friend request on social media, applying to a club, or getting invited to a party, which are all common experiences for those in their 20s and 30s. Importantly, participants were instructed to put themselves in the shoes of the main character by thinking and feeling as if they were actually experiencing the situation. After reading the scenario, the participants were asked to recall personal experience of exclusion (vs. inclusion) and describe in detail how the experience made them feel. Next, participants responded to the manipulation check questions that asked whether they felt excluded or rejected during the experience they recalled on a 7-point Likert scale $(1=$ strongly disagree, $7=$ strongly agree).

The participants then viewed either the other-benefit or the self-benefit version of a print advertisement for upcycling products. In line with prior studies (e.g., White and Peloza, 2009) [22], the self-benefit appeals explicitly illustrated benefits for buyers themselves ("Smart Choice for YOU"), while the other-benefit appeals highlighted altruistic benefits for the society at large ("Smart Choice for the ENVIRONMENT.") in the headline. The "Upcycling" logo was also added in the advertisements. A real brand, Freitag, was introduced as an upcycling fashion brand and the images of two representative products from the brand (a messenger bag and a notebook carrier) were also featured in the advertisement. Given that we used a real brand, all participants were asked to indicate their attitude towards the brand, if any, at the end of the survey. Apart from the appeal type, all other elements of the advertisements remained the same across conditions. We designed these appeals to replicate the appeals commonly employed by eco-friendly brands. To check if the manipulation worked as intended, we asked two questions ("I think the advertisement emphasized self-focused benefits of upcycling products.", "I think the advertisement emphasized other-focused benefits of upcycling products."), using a 7-point Likert scale ( 1 = strongly disagree, 7 = strongly agree).

Finally, to measure how stable (vs. unstable) the participants perceive the exclusion experience to be, we asked the following two questions; "I believe my experience of social exclusion (vs. inclusion) will remain more or less the same even if I try to change it," and "I believe my experience of social exclusion (vs. inclusion) can change through my effort." Here again a 7-point Likert scale $(1=$ strongly disagree, $7=$ strongly agree $)$ was used.

In the final section of the experiment, participants completed a four-item measure of their intentions to purchase upcycling products on a 7-point scale $(1=$ strongly disagree, 7 = strongly agree, Cronbach's Alpha $=0.876$ ); "I am willing to purchase this product", "If I need a bag, I would buy this product.", "I am willing to recommend this product to others.", and "I will consider upcycling products over regular products when purchasing bags." The four items were averaged to form an index for purchase intention: a higher score indicated higher purchase intention $(\alpha=0.876)$. In addition, participants completed demographic measures (e.g., gender, age, and income). The demographic variables did not predict significant variance in the dependent variable (nor did it interact with any other independent variable to predict the dependent variable). 


\subsection{Results}

\subsubsection{Manipulation Check}

In order to confirm whether the social exclusion state and the type of message appeal were properly manipulated, two independent sample t-tests were conducted. The result of the manipulation check on the social exclusion state showed that the socially excluded participants reported feeling excluded or rejected at a significantly higher level $(N=97, M=5.9330, S D=0.970)$ than socially included participants $\operatorname{did}(N=83, M=3.5904$, $S D=1.845)(t=10.876, p<0.001)$ (Table 1$)$. Therefore, it was confirmed that the manipulation of social exclusion state was successful.

Table 1. Manipulation check of social exclusion state.

\begin{tabular}{cccc}
\hline Condition & $\boldsymbol{N}$ & $\boldsymbol{M}$ & $\boldsymbol{S D}$ \\
\hline Social exclusion & 97 & 5.9330 & 0.970 \\
\hline Social inclusion & 83 & 3.5904 & 1.845 \\
\hline$t(p)$ & & $10.876(0.000)^{* * * *}$ & \\
F** $p<0.01$. & &
\end{tabular}

The results of the manipulation check on message appeal type showed that the participants exposed to the self-benefit appeals agreed with the statement that the ad was focused on self-benefit at a significantly higher level $(N=81, M=4.47, S D=1.526)$ than those exposed to the other-benefit appeals $(N=99, M=2.77$ and $S D=1.406)(t=-7.711$, $p<0.001)$. Conversely, participants exposed to the other-benefit appeals agreed with the statement that the ad was focused on other-benefit at a significantly higher level $(N=99$, $M=5.06, S D=1.557)$ than those exposed to the self-benefit appeals $(N=81, M=3.46$, $S D=1.509)(t=6.993, p<0.001)$ (Table 2$)$. Therefore, it was confirmed that the self-benefit appeal and the other-benefit appeal were successfully manipulated in accordance with the experimental conditions.

Table 2. Manipulation check of message appeal type.

\begin{tabular}{ccccc}
\hline Question & Condition & $N$ & $M$ & $S D$ \\
\hline The ad emphasized & other-benefit appeal & 99 & 2.77 & 1.406 \\
self-focused benefits & self-benefit appeal & 81 & 4.47 & 1.526 \\
\hline$t(p)$ & \multicolumn{4}{c}{$-7.711(0.000)^{* * *}$} \\
\hline $\begin{array}{c}\text { The ad emphasized } \\
\text { other-focused benefits }\end{array}$ & other-benefit appeal & 99 & 5.06 & 1.557 \\
\hline$t(p)$ & self-benefit appeal & 81 & 3.46 & 1.509 \\
\hline$* * * 0.993(0.000)^{* * *}$ & & \\
\hline & &
\end{tabular}

\subsubsection{Purchase Intention of Upcycling Products}

Two-way ANOVA was conducted to test the difference in purchase intention of upcycling products depending on social exclusion state (exclusion vs. inclusion) and message appeal type (other-benefit vs. self-benefit). The results confirmed the Hypothesis 1 that the social exclusion state and message appeal type will interact to influence purchase intention. ( $F=15.666, p<0.001)$ (Table 3$)$. As shown in Figure 1, participants who were induced to feel social excluded reported higher level of purchase intention when exposed to self-benefit appeal $(M=4.506)$ as compared to other-benefit appeal $(M=3.080)$. 
Table 3. Interaction effect between social sate and appeal type.

\begin{tabular}{|c|c|c|c|c|c|c|}
\hline DV & IV & SS & d.f. & MS & $F(p)$ & $p$ \\
\hline \multirow{8}{*}{$\begin{array}{l}\text { Purchase } \\
\text { intention }\end{array}$} & Modified Model & 50.334 & 3 & 16.778 & 9.008 & 0.000 \\
\hline & intercept & 2582.507 & 1 & 2582.507 & 1400.441 & 0.000 \\
\hline & Appeal type & 16.887 & 1 & 16.887 & 9.157 & $0.003^{* *}$ \\
\hline & Social state & 0.120 & 1 & 0.120 & 0.065 & 0.799 \\
\hline & Appeal type $\times$ Social state & 28.890 & 1 & 28.890 & 15.666 & $0.000^{* * *}$ \\
\hline & error & 324.556 & 176 & 1.844 & & \\
\hline & sum & 2955 & 180 & & & \\
\hline & Modified sum & 374.890 & 179 & & & \\
\hline
\end{tabular}

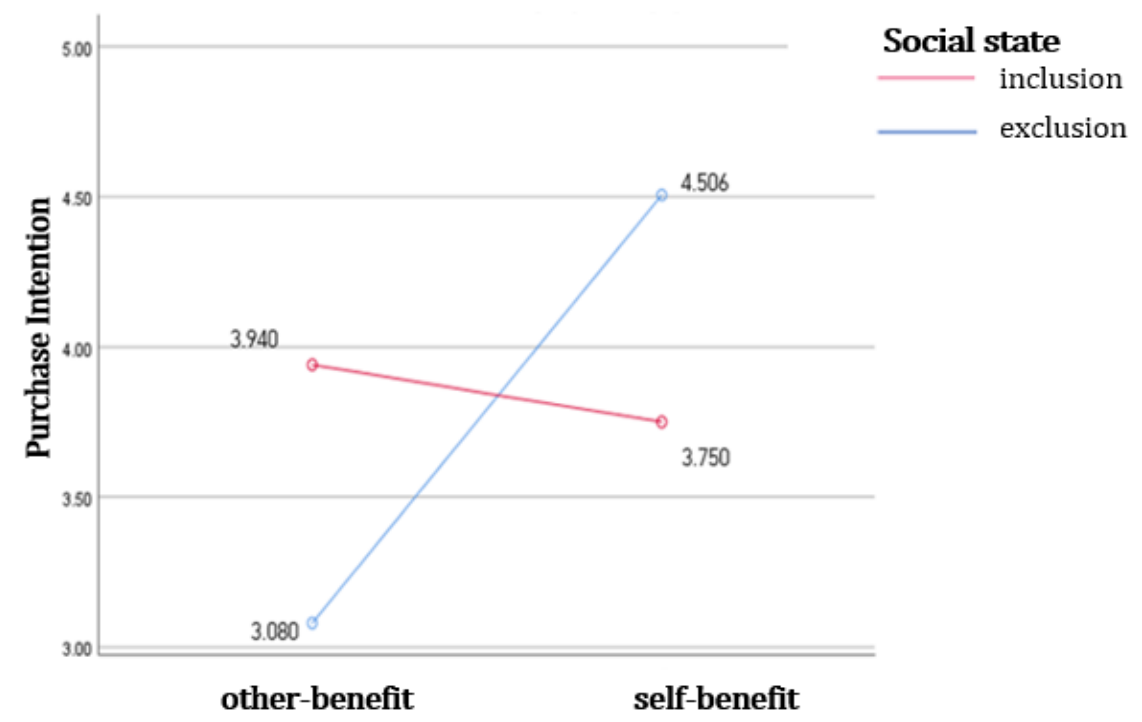

Figure 1. Purchase intention of upcycling products as a function of social state and message appeal.

To formally test the effect of message appeal type within each social condition, an independent sample $t$-test was conducted separately for the social exclusion and social inclusion condition. First, for socially excluded participants, the purchase intention for upcycling products was significantly higher for those exposed to self-benefit appeals $(M=4.5057)$ as compared to other-benefit appeals $(M=3.0802)(t=-4.9473, p<0.001)$ (Table 4). This is consistent with the Hypothesis 1a. On the other hand, for socially included participants, there was no statistically significant difference in purchase intention for upcycling products as a function of appeal type $(t=0.673, p=0.503)$ (Table 5).

Table 4. Self-benefit appeals are more effective than other-benefit appeals in encouraging purchase intentions for socially excluded participants $(n=97)$.

\begin{tabular}{ccccc}
\hline & Appeal Type & $N$ & $M$ & $S D$ \\
\hline Upcycling products & Other-benefit appeal & 53 & 3.0802 & 1.3630 \\
Purchase intention & Self-benefit appeal & 44 & 4.5057 & 1.4552 \\
\hline$t(p)$ & \multicolumn{4}{c}{$-4.9473(0.000)^{* * *}$} \\
*** $p<0.01 .^{*}$
\end{tabular}


Table 5. Self-benefit appeals are NOT more effective than other-benefit appeals in encouraging purchase intentions for socially included participants $(n=83)$.

\begin{tabular}{ccccc}
\hline & Appeal Type & $\boldsymbol{N}$ & $\boldsymbol{M}$ & $\boldsymbol{S D}$ \\
\hline Upcycling products & Other-benefit appeal & 46 & 3.9402 & 1.382 \\
Purchase intention & Self-benefit appeal & 37 & 3.7500 & 1.190 \\
\hline$t(p)$ & \multicolumn{3}{c}{$0.673(0.503)$} \\
\hline
\end{tabular}

\subsubsection{Perceived Stability of Social Exclusion}

Next, we investigated whether the observed difference in purchase intention of upcycling products between self-benefit versus other-benefit appeal condition is moderated by how stable participants perceived their exclusion experience to be. To test this, we limited our analysis to the participants who received social exclusion manipulation. First, we calculated the perceived stability score based on participants' response to the two questions asking how stable they think their exclusion experience will be over time and situation (Cronbach's Alpha $=0.651$ ). To test the moderating effect of perceived stability, we ran Process Model 1 (Hayes, 2013) with purchase intention as dependent variable and appeal type as independent variable (other-benefit appeal $=1$, self-benefit appeal $=2$ ). The results revealed significant interaction between message appeal type and perceived stability (Coefficient $=0.7108, t=4.4147, p<0.01$, CI [0.3911, 1.0305]) $($ Table 6). Thus, the Hypothesis 2 was supported.

Table 6. Moderating effect of perceived stability among socially excluded participants.

\begin{tabular}{ccccccc}
\hline & Coefficient & Se & $\boldsymbol{t}$ & $\boldsymbol{p}$ & LLCI & ULCI \\
\hline Appeal type & -1.3426 & 0.6431 & -2.0876 & 0.0396 & -2.6198 & -0.0655 \\
Perceived stability & -1.1152 & 0.2243 & -4.9713 & 0.000 & -1.5607 & -0.6697 \\
Interaction & 0.7108 & 0.1610 & 4.4147 & 0.000 & 0.3911 & 1.0305 \\
\hline
\end{tabular}

Specifically, among socially excluded participants, the higher the perceived stability of social exclusion, the stronger the positive (+) effect of self-benefit appeal on the purchase intention of upcycling products compared to the other-benefit appeal. The size of the 'Effect' increased from 1.1451 to 3.6328 as the value of perceived stability increased from the median point of 3.50 to 7.00 (Table 7). That is, among socially excluded participants, those who believed their exclusion experience to be rather stable, the purchase intention of upcycling products was significantly higher for self-benefit appeal than for other-benefit appeal (Figure 2). However, for those who believed their exclusion experience to be not particularly stable, the purchase intention of upcycling products was not significantly different between self-benefit appeal and other-benefit appeal. Thus, the Hypothesis $2 \mathrm{a}$ was supported.

Table 7. Effect size of self-benefit appeal (in comparison to other-benefit appeal) on purchase intention at different levels of perceived stability.

\begin{tabular}{ccccccc}
\hline Perceived Stability & Effect & Se & $\boldsymbol{t}$ & $\boldsymbol{p}$ & LLCI & ULCI \\
\hline 1.0000 & -0.6319 & 0.5013 & -1.2604 & 0.2107 & -1.6274 & 0.3637 \\
2.0000 & 0.0789 & 0.3753 & 0.2103 & 0.8339 & -0.6663 & 0.8242 \\
3.5000 & 1.1451 & 0.2689 & 4.2577 & 0.000 & 0.6110 & 1.6792 \\
4.6000 & 1.9270 & 0.3102 & 6.2117 & 0.000 & 1.3109 & 2.5430 \\
6.0000 & 2.9221 & 0.4662 & 6.2672 & 0.000 & 1.9962 & 3.8479 \\
7.0000 & 3.6328 & 0.6051 & 6.0038 & 0.000 & 2.4312 & 4.8344 \\
\hline
\end{tabular}




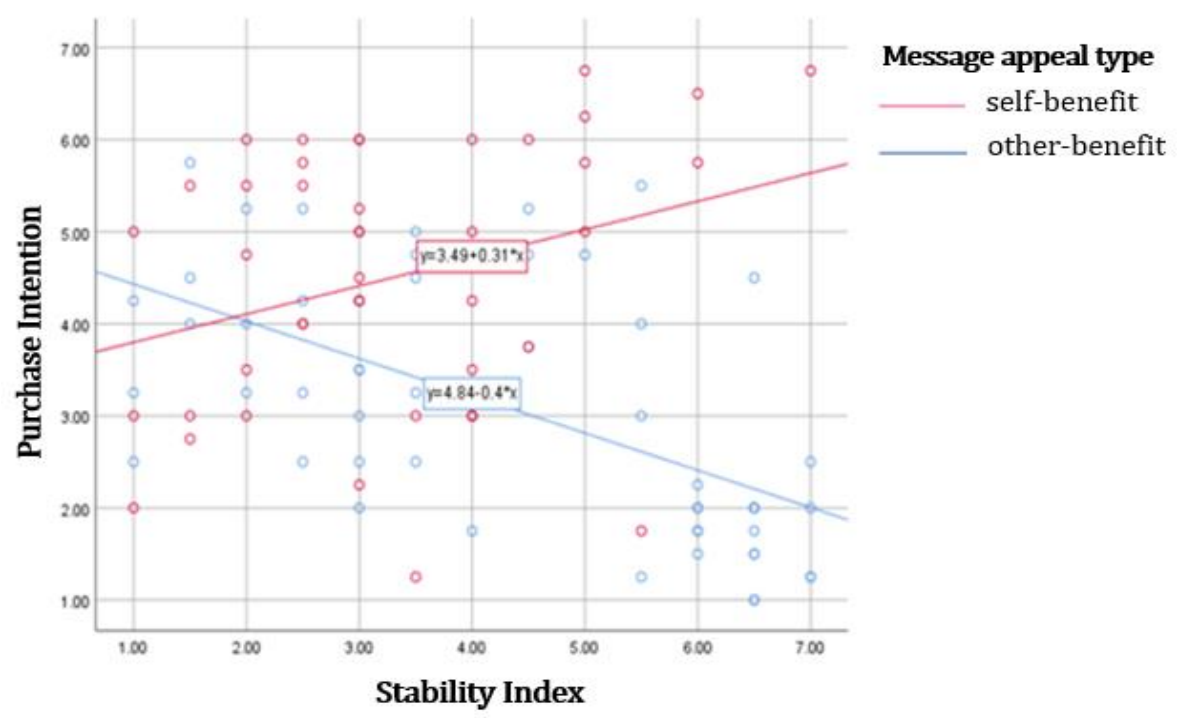

Figure 2. Scatter plot of purchase intention by perceived stability and message appeal types in social exclusion condition.

\section{Discussion}

\subsection{Research Summary and Implications}

We conducted an experimental study to examine the effect of social exclusion on consumer's response to self-benefit vs. other-benefit marketing appeals for eco-friendly upcycling products. The results suggest that the effectiveness of self- versus other-benefit appeals depends on consumers' psychological state, specifically whether they are feeling socially excluded or not. When participants felt socially excluded, self-benefit appeals were more effective than other-benefit appeals in encouraging positive purchase intentions. Importantly, the effect of social exclusion was shown to be moderated by how stably participants thought they would feel socially excluded. The more persistent participants perceived their exclusion experience would be, the more positively they responded to selfbenefit appeals as compared to other-benefit appeals. On the other hand, when participants were feeling socially accepted, there was no difference in the effectiveness of self- versus other-benefit appeals.

In promoting eco-friendly upcycling products, some practitioners believe in the effectiveness of other-benefit appeals while other practitioners believe in effectiveness of self-benefit appeals. The findings from the current research suggest that existing understanding of what type of appeals are most effective in garnering consumer support may be oversimplified. The current research also challenges and expands on the understanding of how consumers' perception or appraisal of their psychological state can affect consumers' subsequent judgment and choice.

The findings from current research provide important opportunities for upcycling brands to increase the efficacy of their marketing initiatives. In particular, marketers should consider target consumers' psychological state activated in a given context. If it is reasonable to assume that consumers might feel socially excluded, marketers should use appeals that highlight the benefits potential consumers themselves will obtain by purchasing the upcycling products. Especially, if there are reasons to believe that consumers will think their current psychological state (i.e., feeling socially excluded) will last, marketers can be more confident in their choice of promotion messages highlighting benefits to self.

Tailoring marketing appeals to match consumers' psychological state is no longer unrealistic. Due to advances in digital technology and various analytic techniques, modern marketers have access to consumers' psychological states. By tracking a broad variety of digital footprints collected in real time from spoken and written language online, smartphone sensor data, and wearable devices, marketers can predict consumers' moods and emotions (Matz and Netzer, 2017) [29]. The ability to assess consumers' psychological states 
provides opportunities to personalize marketing content to the immediate psychological needs of consumers. Context-aware recommendation systems, as an illustration, already use information on consumers' mood or emotions to successfully improve recommendations for music, movies, and images.

\subsection{Limitations and Future Research}

Despite its contributions, the current research is not free from limitations. First, the participants in our experiment were consumers in their 20s and 30s. Future research should examine whether the results hold true for population at large. Second, some researchers noted that there are many possible nuances of social exclusion; for instance, being rejected, being ignore, and being lonely are not the same and cultural norms play an important role in shaping their effects (e.g., Lee \& Shrum, 2012; Lee, Shrum \& Yi, 2017 Molden et al., 2009) [31-33]. In the current experiment, we only investigated the effect of being rejected on consumers' response to upcycling products promoted by different appeals. Future research should investigate the effect of being ignored or being chronically lonely. Third, we only used one version of advertisement message for our manipulation. Future research should try to use different manifestation of self- vs. other benefit messages to increase the generalizability of the findings.

Finally, we made upcycling products the target of our research because literature review suggested that there were little research examining the efficacy of different promotional messages for upcycling products, let alone impact of psychological factors therein. However, we believe that the current findings may have relevance for much broader industry than upcycling. Indeed, purchasing fair-trade products, recycling, and many other consumption behaviors, involve consideration for others' benefit. Future research should examine the comparative effectiveness of self-benefit versus other-benefit appeals in encouraging behaviors that are beneficial to both self and others and whether psychological states moderate consumer responses to such appeals.

Author Contributions: Conceptualization, S.H. and A.Y.; Data curation, A.Y;; Formal analysis, A.Y. and S.H.; Project administration, A.Y.; Original draft preparation, A.Y.; Writing, S.H. All authors have read and agreed to the published version of the manuscript.

Funding: This research received no external funding.

Institutional Review Board Statement: Ethical review and approval were waived for this study, due to the minimal risk involved.

Informed Consent Statement: Informed consent was obtained from all subjects involved in the study.

Data Availability Statement: The data used in the research has been uniquely generated through the scheme of the experiment. It will be available upon request.

Conflicts of Interest: The authors declare no conflict of interest.

\section{References}

1. Why Clothes Are so Hard to Recycle. Available online: https://www.bbc.com/future/article/20200710-why-clothes-are-sohard-to-recycle (accessed on 13 July 2020).

2. Singh, J.; Sung, K.; Cooper, T.; West, K.; Mont, O. Challenges and Opportunities for Scaling up Upcycling businesses-The Case of Textile and Wood Upcycling Businesses in the UK. Resource. Conserv. Recycl. 2019, 150, 104439. [CrossRef]

3. About 1.7 Billion People Belong to the Global "Consumer Class". Available online: https://www.nationalgeographic.com/ environment/article/consumerism-earth-suffers (accessed on 12 January 2004).

4. Baumeister, R.F.; DeWall, C.N.; Ciarocco, N.J.; Twenge, J.M. Social Exclusion Impairs Self-Regulation. J. Personal. Soc. Psychol. 2005, 88, 589-604. [CrossRef]

5. Kwilinski, A.; Vyshnevskyi, O.; Dzwigol, H. Digitalization of the EU Economies and People at Risk of Poverty or Social Exclusion. J. Risk Financ. Manag. 2020, 13, 142. [CrossRef]

6. Sjåstad, H.; Zhang, M.; Masvie, A.E.; Baumeister, R. Social exclusion reduces happiness by creating expectations of future rejection. Self Identity 2021, 20, 116-125. [CrossRef]

7. Williams, K.D. Ostracism. Annu. Rev. Psychol. 2007, 58, 425-452. [CrossRef] 
8. $\quad$ Primack, B.A.; Shensa, A.; Sidani, J.E.; Whaite, E.O.; yi Lin, L.; Rosen, D.; Colditz, J.B.; Radovic, A.; Miller, E. Social Media use and Perceived Social Isolation among Young Adults in the US. Am. J. Prev. Med. 2017, 53, 1-8. [CrossRef]

9. Baumeister, R.F.; Leary, M.R. The Need to Belong: Desire for Interpersonal Attachments as a Fundamental Human Motivation. Psychol. Bull. 1995, 117, 497-529. [CrossRef] [PubMed]

10. DeWall, C.N.; Twenge, J.M.; Gitter, S.A.; Baumeister, R.F. It's the Thought that Counts: The Role of Hostile Cognition in Shaping Aggressive Responses to Social Exclusion. J. Personal. Soc. Psychol. 2009, 96, 45-59. [CrossRef]

11. Twenge, J.M.; Baumeister, R.F.; DeWall, C.N.; Ciarocco, N.J.; Bartels, J.M. Social Exclusion Decreases Prosocial Behavior. J. Personal. Soc. Psychol. 2007, 92, 56-66. [CrossRef]

12. Gardner, W.L.; Pickett, C.L.; Jefferis, V.; Knowles, M. On the Outside Looking in: Loneliness and Social Monitoring. Personal. Soc. Psychol. Bull. 2005, 31, 1549-1560.

13. Maner, J.K.; DeWall, C.N.; Baumeister, R.F.; Schaller, M. Does Social Exclusion Motivate Interpersonal Reconnection? Resolving the "Porcupine Problem". J. Personal. Soc. Psychol. 2007, 92, 42-55. [CrossRef]

14. Kim, Y.; Han, S. The effect of the social exclusion experience on the consumer's response to the situation where they consume the same product as others. Korean J. Consum. Advert. Psychol. 2014, 15, 555-574.

15. Mead, N.L.; Baumeister, R.F.; Stillman, T.F.; Rawn, C.D.; Vohs, K.D. Social Exclusion Causes People to Spend and Consume Strategically in the Service of Affiliation. J. Consum. Res. 2011, 37, 902-919.

16. Williams, K.D.; Cheung, C.K.; Choi, W. Cyberostracism: Effects of being Ignored over the Internet. J. Personal. Soc. Psychol. 2000, 79, 748-762. [CrossRef]

17. Twenge, J.M.; Baumeister, R.F.; Tice, D.M.; Stucke, T.S. If You can't Join them, Beat them: Effects of Social Exclusion on Aggressive Behavior. J. Personal. Soc. Psychol. 2001, 81, 1058-1069.

18. Wan, E.W.; Xu, J.; Ding, Y. To be Or Not to be Unique? The Effect of Social Exclusion on Consumer Choice. J. Consum. Res. 2014, 40, 1109-1122.

19. Brunel, F.F.; Nelson, M.R. Explaining Gendered Responses to "help-Self" and "help-Others" Charity Ad Appeals: The Mediating Role of World-Views. J. Advert. 2000, 29, 15-28. [CrossRef]

20. Fisher, R.J.; Vandenbosch, M.; Antia, K.D. An Empathy-Helping Perspective on Consumers' Responses to Fund-Raising Appeals. J. Consum. Res. 2008, 35, 519-531. [CrossRef]

21. Kim, Y.; Kim, Y. The Effects of Processing Fluency in Prosocial Campaigns: Effort for Self-Benefit Produces Unpleasant Feelings. Front. Psychol. 2020, 11, 1221. [CrossRef] [PubMed]

22. White, K.; Peloza, J. Self-Benefit Versus Other-Benefit Marketing Appeals: Their Effectiveness in Generating Charitable Support. J. Mark. 2009, 73, 109-124. [CrossRef]

23. De Groot, J.I.; Steg, L. Value Orientations to Explain Beliefs Related to Environmental Significant Behavior: How to Measure Egoistic, Altruistic, and Biospheric Value Orientations. Environ. Behav. 2008, 40, 330-354. [CrossRef]

24. Stern, P.C. New Environmental Theories: Toward a Coherent Theory of Environmentally Significant Behavior. J. Soc. Issues 2000, 56, 407-424. [CrossRef]

25. Peattie, K.; Crane, A. Green Marketing: Legend, Myth, Farce or Prophesy? Qual. Mark. Res. Int. J. 2005, 8, 357-370. [CrossRef]

26. Taylor, S.; Todd, P. Understanding Household Garbage Reduction Behavior: A Test of an Integrated Model. J. Public Policy Mark. 1995, 14, 192-204. [CrossRef]

27. Baek, T.H.; Yoon, S.; Kim, S.; Kim, Y. Social exclusion influences on the effectiveness of altruistic versus egoistic appeals in charitable advertising. Mark. Lett. 2019, 30, 75-90. [CrossRef]

28. Su, L.; Jiang, Y.; Chen, Z.; DeWall, C.N. Social Exclusion and Consumer Switching Behavior: A Control Restoration Mechanism. J. Consum. Res. 2017, 44, 99-117. [CrossRef]

29. Matz, S.C.; Netzer, O. Using Big Data as a Window into Consumers' Psychology. Curr. Opin. Behav. Sci. 2017, 18, 7-12. [CrossRef]

30. Weiner, B. Attribution, Emotion, and Action. In Handbook of Motivation and Cognition: Foundations of Social Behavior; Sorrentino, R.M., Higgins, E.T., Eds.; Guilford Press: New York, NY, USA, 1986; pp. 281-312, ISBN 0-89862-667-6.

31. Lee, J.; Shrum, L.J. Conspicuous Consumption Versus Charitable Behavior in Response to Social Exclusion: A Differential Needs Explanation. J. Consum. Res. 2012, 39, 530-544. [CrossRef]

32. Lee, J.; Shrum, L.J.; Yi, Y. The Role of Cultural Communication Norms in Social Exclusion Effects. J. Consum. Psychol. 2017, 27, 108-116. [CrossRef]

33. Molden, D.C.; Lucas, G.M.; Gardner, W.L.; Dean, K.; Knowles, M.L. Motivations for Prevention or Promotion Following Social Exclusion: Being Rejected Versus being Ignored. J. Personal. Soc. Psychol. 2009, 96, 415-431. [CrossRef] 